\title{
MATERIAIS DIDÁTICOS PARA MEDIAÇÃO DO DESIGN NO PROCESSO DE APRENDIZAGEM NA TERCEIRA IDADE
}

Bruno Serviliano Santos Farias

Universidade Federal do Maranhão

brunoserviliano@gmail.com

Andréa Katiane Ferreira Costa

Universidade Federal do Maranhão

andrea.katianefc@gmail.com

Arthur Marques

Universidade Federal do Maranhão

arthurgarre@gmail.com

\author{
Ana Luiza Lima Rodrigues \\ Universidade Federal do Maranhão \\ analuizalimarodrigues@gmail.com \\ Raquel Gomes Noronha \\ Universidade Federal do Maranhão \\ raquelnoronha79@gmail.com \\ Márcio James Soares Guimarães \\ Universidade Federal do Maranhão \\ falecommg@gmail.com
}

Resumo: Este trabalho faz parte do Projeto de pesquisa "Mediação do design no processo de aprendizagem na terceira idade" desenvolvido pelo NIDA Núcleo de Pesquisa em Imagens, Design e Antropologia, do curso de Design, da UFMA. Este segmento da pesquisa se ocupa em analisar os artefatos didáticos adotados pela Universidade da Terceira Idade da UFMA. Para tal, foi empregada a pesquisa etnográfica através das observações em salas de aulas, entrevistas com os docentes, bem como análise gráfico-morfológica dos artefatos didáticos. A conclusão da pesquisa aponta à influência do processo de envelhecimento e do contexto social no processo de aprendizagem como problemas de visão e baixa escolaridade. Sinaliza, ainda, a importância dos elementos gráficos como tipografia, contraste e elementos pictóricos no planejamento dos artefatos didáticos.

Palavras-chave: Design gráfico. Processo de Aprendizagem. Terceira Idade

Abstract: This report is part of the research project "Mediation of Design in the learning process in old age" developed by NIDA - Research Centre for Images, Design and Anthropology of the design course in UFMA. This segment of the research is concentrated in to analyze the didactic artifacts adopted by the University of the Third Age in the UFMA. Thus, was used the ethnographic research with observations in lessons, interviews with teachers, as well as morphological graphical analysis of didactic artifacts. The conclusion of the research indicates the influence of the aging process and the social context in the learning process such vision problems and low education. Also signals the importance of graphics and typography, contrast and pictorial elements in the planning of didactic artifacts.

Keywords: Graphic Design. Learning Process. Seniors 


\section{INTRODUÇÃO}

Este trabalho integra o Projeto de Pesquisa "Mediação do design no processo de aprendizagem na terceira idade" desenvolvido pelo NIDA - Núcleo de Pesquisa em Imagens, Design e Antropologia, do curso de Design, da UFMA - Universidade Federal do Maranhão, o qual se ocupa em analisar o ambiente de ensino da UNITI Universidade Integrada da Terceira Idade da UFMA, a partir da pesquisa etnográfica, das observações em salas de aulas e entrevistas com os docentes.

A UNITI é um espaço onde são desenvolvidas ações educativas baseadas na promoção dos idosos, considerando fatores sociais, psicológicos, comportamentais e emocionais, buscando motivações e interesses para esse público. Nos últimos anos, o idoso vem sendo valorizado em diferentes áreas das ciências, bem como em alguns segmentos da sociedade. O processo de envelhecimento se constitui atualmente em uma preocupação mundial e várias pesquisas e políticas públicas estão sendo realizadas com o intuito de gerar qualidade de vida para a pessoa idosa.

Entende-se a velhice como sendo uma faixa da população a partir dos 60 anos. Este público está em crescimento, cerca de 3,5\% ao ano, segundo o IPEA. Comparando com as gerações de outras épocas, percebe-se que a carga de trabalho é distinta das condições oferecidas às últimas duas gerações. Era comum, no passado, projetar uma velhice sombria, como uma fase para se pagar os pecados da juventude, onde a velhice era vista como um depósito de excessos da juventude. (SKINNER, 1984). No entanto, hoje, a pessoa idosa está relacionada às atividades sociais e ao lazer, como forma não só de se reconciliar com a velhice, como afirma Skinner (1984), mas também de recuperar parte de sua importância no convívio social.

Oportunamente, o país tem promovido várias ações no sentido de valorizar essa faixa etária. Em 2003, foi sancionado o Estatuto do idoso, com o objetivo de ampliar os direitos e a qualidade de vida dos cidadãos com idade acima de 60 anos, o que inclui ações efetivas tanto do Estado, como também da sociedade, que tem responsabilidades inalienáveis quanto à vida dos brasileiros que envelheceram. (SHIRAIWA, 2008).

Segundo assertiva de Shiraiwa (2008), os idosos podem apresentar dificuldades para manter a atenção, armazenar informações na memória de trabalho, processar rapidamente informações, formular conclusões, fazer interpretações, codificar e compreender determinados discursos. Esses declínios cognitivos podem ser acentuados por hábitos de vida como: ambiente de trabalho estressante, falta de condicionamento físico, depressão, estresse, uso indevido de medicamentos entre outros. Tais declínios fisiológicos e cognitivos decorrentes da idade forjam uma tendência em distorcer a imagem do idoso como cidadão atuante.

Com maior perspectiva e qualidade de vida aliado ao amparo legal e ações afirmativas, milhares de pessoas idosas querem continuar suas atividades na sociedade, não ficando somente dentro de casa inativo. Essas ações afirmativas promovidas pelo governo e instituições privadas têm o intuito de manter esse público conectado ativamente com o seu meio social. Um exemplo são os cursos universitários para a Terceira Idade. A educação pode reinserir o idoso às atividades sociais, bem como recuperar sua subjetividade, permitindo-lhe exercer diversos papéis: sociais, emocionais, psicológicos, entre tantos outros.

Assim, ao manter o olhar sobre a educação de pessoas na terceira idade, percebe-se a necessidade de pensar em questões mais abrangentes como: condição 
física fragilizada pelo tempo, a estrutura familiar vulnerável e despreparada para lidar com essa situação e a privação material provocada pela situação financeira.

Contemplando essas questões, há o Projeto de Extensão desenvolvida pela UFMA voltado para o ensino e a reinserção social de pessoas acima de 50 anos: a Universidade Integrada da Terceira Idade (UNITI). Desde 1995, através da parceria entre as Universidades Federal e Estadual do Maranhão, do Serviço Social do Comércio e da Secretaria de Planejamento, Orçamento e Gestão do Maranhão, foi criado o Projeto UNITI que representa, hoje, um espaço para a ampla repercussão social, tendo como objetivo oferecer à população da melhor idade a prática de atividades que lhes possibilitem fortalecer a participação social e política, assumir conscientemente o processo de envelhecimento e gozar de pleno exercício de sua cidadania, criando condições para o resgate da autoconfiança e da autoestima. Seu público alvo constituise de pessoas maiores de 50 anos, procedentes dos diversos segmentos da sociedade e vinculadas aos Programas e Órgãos Conveniados.

Nesse sentido, o design pode contribuir com os processos de aprendizagem na terceira idade ao desenvolver artefatos didáticos adequados, mediando a relação ensinoaprendizagem e gerando um ambiente pedagógico mais seguro e eficiente. Tais intervenções envolvem a investigação das barreiras de aprendizagem bem como os fatores emocionais, a partir da análise das experiências dos alunos e seu grau de participação nas aulas, pois possibilitam compreender os aspectos emocionais e o impacto que tais aspectos têm no ensino.

Esse estudo faz parte de um projeto maior que pesquisa as formas de mediação da educação na terceira idade. Para esse artigo foi realizada a primeira etapa do projeto, Pesquisa Etnográfica com o objetivo de compreender as práticas de ensino no ambiente de aprendizagem, entender a relação entre professores e alunos da terceira idade e descrever os artefatos didáticos utilizados. Para tanto, foram empregadas as técnicas de observação e entrevistas, priorizando os aspectos gráficos: tipografia e elementos pictóricos.

\section{CONCEITOS E PRINCÍPIOS DA TIPOGRAFIA E DA LINGUAGEM VISUAL}

Até alguns séculos atrás, ler era um privilégio de poucos - ou porque o processo de impressão não era popular e acessível ou porque poucos eram alfabetizados-. Hoje, tanto a educação se tornou direito de todos como o processo de impressão se popularizou, embora em muitos lugares esse direito e esse recurso tecnológico ainda seja um privilégio restrito. Dondis (1997) nos lembra de que somos alfabetizados verbalmente, por exemplo, as letras que representam os fonemas são materiais de construção da nossa língua, pois através delas formamos sílabas, palavras e frases. Frutiger (2007) descreve esse processo de leitura na infância, aduzindo que é comum soletrar os fonemas separadamente e, depois, com o hábito da leitura, concentramo-nos em palavras e frases. Nesse sentido, podemos perceber que a letra, no processo de leitura, vai se transformando em alguma outra coisa, talvez mais visual e menos verbal. A letra como símbolo verbal nos permite ser alfabetizados, entretanto, a letra como elemento pictórico pode facilitar ou dificultar o processo de alfabetização e, consequentemente, a leitura.

Letras, palavras, textos e prática da leitura são aspectos da mancha gráfica que, segundo Lupton (2013), se relaciona com o principal bloco textual. As letras, impressas em uma página permitem várias configurações através de seus estilos tipográficos, do espaçamento entre as palavras, do tamanho das letras, do alinhamento do texto, entre 
outras questões gráficas que se relacionam mais com o aspecto pictórico do que o verbal. Tais questões são instrumentos da comunicação visual e, muitas vezes, a ênfase está na clareza absoluta, outras na liberdade estética.

A clareza está relacionada, segundo Farias (2013), em duas questões: legibilidade, desenho dos tipos (letras empregadas no material gráfico) e leiturabilidade, compreensão do texto e da linguagem utilizada. Assim, o melhor estilo de letra impressa seria aquele em que todos podem decifrar rapidamente. Essa lógica funcionalista é percebida no ocidente, principalmente no início do século $X X$, onde foram adotadas as letras latinas como padrão internacional. Tal padrão se tornou material de consumo bem como uma fonte de conforto na era da informação, auxiliando a compreensão de textos com o mínimo de resistência cognitiva e o máximo de velocidade.

Nessa perspectiva histórica, o século XX marcou o fim de uma transição que já ocorria há cinco séculos: a influência dos livros manuscritos medievais e os livros herdeiros da revolução industrial. O primeiro resguardava valores estéticos clássicos e o uso de elementos decorativos em uma estética de obra de arte para ser contemplado. 0 segundo, mesmo com variações tipográficas e extensões, como afirma Frutiger (2007), sempre manteve reconhecível a forma básica do caractere, preservando certos aspectos dimensionais, com exceção dos desvios de letras ornamentais e decorativas que possuem apelo pictórico. No século XIX foram realizados estudos sobre a legibilidade por tipógrafos e psicólogos da percepção que passaram a estudar de forma mais sistemática até desenvolverem conhecimentos próprios e distintos.

$\mathrm{Na}$ tipografia, a legibilidade se baseou no poder da comunicação e na acomodação do texto o que foi denominado de "espírito da tipografia moderna" pelo designer McMurtrie (2010, p. 40) em 1929. Interferindo na legibilidade estaria o espaço entre as linhas, o tamanho das letras e os estilos tipográficos. Baseado no reconhecimento das letras e assombrado pela lógica moderna surgiu um novo estilo tipográfico, esquadrinhada pela forma e pela função. Jan Tschichold (2010) em 1930 defendia a padronização dos formatos impressos, defendeu ainda o estilo grotesco pela composição simples que facilitaria a leitura. Ele até admitiu o uso de outros estilos, entretanto, nesse plano cartesiano que ele chamou de material impresso, se priorizava, prima facie, o contraste tipográfico, ou em outras palavras, variação e legibilidade.

Frutiger (2007) citou a largura e a espessura como meios de manter a proporção e gerar variações tipográficas necessárias à mancha gráfica. A largura das letras adquiriu uma proporção determinada depois de um século de uso, segundo esse autor. A silhueta "normal" se daria pela relação entre traços verticais e os espaços brancos internos. Para ilustrar a força do racionalismo presente no século XX, o designer gráfico ainda desenhou a letra " $H$ " e comentou que na forma regular a largura seria de $1 / 5$ menor que a altura. Ao comentar a largura e espessura, Araújo (2008) se preocupou com a superfície total de impressão e enfatizou o traço do olho dos tipos. Segundo ele, a maior ou menor dimensão do olho suscitaria um problema de espaço, assim, poderia experimentar a redução do corpo do tipo que, na prática, influenciaria as condições de legibilidade da página.

As variações de proporção formariam famílias tipográficas, como por exemplo: variações de peso, negrito, condensada, expandida, mas com o mesmo estilo de escrita. Assim, poderiam manter o mesmo padrão, como defendia Tschichold. Frutiger (2007, p. 149), quando afirmou que a proporção "normal", regular, é empregada como maior recorrência em textos longos e suas variações em informações breves. A espessura da proporção normal de letras tem aproximadamente $15 \%$ de sua altura. Traços mais 
delgados são avaliados como light e mais espessos como semibold ou bold que não são adequados em grandes blocos textuais. Willian Morris (BIERUT et al, 2010, p. 2) há 120 anos já se levantava contra o uso de tipos condensados em textos afirmando que comprometia a legibilidade.

O grau de precisão dos desenhos das letras, segundo Frutiger (2007), estaria ancorado na união das letras, como uma fotografia, na qual se compararia com o esquema mental. Um defeito mínimo do desenho poderia prejudicar a imagem criada e assim confundir o " $\mathrm{c}$ " com " $\mathrm{o}$ " ou " $\mathrm{e}$ ", ou mesmo " $\mathrm{h}$ " com " $\mathrm{n}$ ". O prolongamento das ascendentes e descendentes poderia contribuir para diferenciar as letras e facilitar o reconhecimento das palavras. Além disso, Frutiger (2007) ainda reúne outras questões tipográficas, como: aberturas internas a fim de melhorar a legibilidade, a dispensabilidade do uso de serifas por não serem decisivas ao reconhecimento, tendo em vista não constituir um elemento diferenciador, no entanto poderiam guiar o olhar ligando as letras.

Tais questões indicariam que a verdadeira forma desejada, consciente ou não pelo leitor, seria aquela que se fixaria profundamente por meio do hábito de leitura de livros, jornais e revistas. Willian Golden (2010, p. 125) comenta a importância histórica do jornal e revista. O jornal nos ensinou, segundo ele, a informar com rapidez, instintivamente com manchetes, imagens e três parágrafos de texto. A revista, por ter um público mais seleto, pode ser mais vagarosa com a informação e assim empregar textos mais longos e imagens mais "imaginativas". Herb Lubalin (2010) comenta que a televisão influenciou os hábitos de leitura nos acostumando mais a olhar imagens e ler menos textos. As relações entre texto e imagens e o emprego de cores se relacionam com a linguagem visual.

Poderíamos deduzir nessa linha de raciocínio linear que existiria um arquétipo construído pelas nossas experiências, memórias e repertório de uma escrita mais legível com características essenciais e, com isso, se poderia verificar quais são essas características e como elas ressoariam nos estilos tipográficos. Meürer et al (2014) destacou alguns desses princípios como: usar os tipos clássicos, evitar o uso exclusivo de maiúsculas, evitar o uso de tipos leves ou muito pesados.

Além do elemento verbal, o uso de palavras no bloco textual pode utilizar outros elementos visuais. Horn (1998) define linguagem visual como a integração entre palavras, imagens e formas configurando uma unidade ao comunicar algo. Segundo esse autor, quando esses dois elementos são usados separadamente eles não configuram uma verdadeira linguagem visual, desse modo, cada elemento despertará um significado com pistas visuais, mediante suas propriedades como cor, escala, textura, forma, entre outras.

Qualquer que seja as pistas visuais das representações, o seu significado bem como a aparência final é uma construção. Nesse sentido, Gombrich (2012) relacionava a facilidade em perceber a facilidade de construção de significado e tal raciocínio nos abriu possibilidades de levantar várias questões sobre o domínio da linguagem para facilitar a construção, o uso de um vocabulário acessível para possibilitar a percepção, bem como o uso de redundância para oferecer o maior número de pistas visuais. Tomemos como exemplo um público que não tem o hábito de leitura; o uso de imagens como fotos e ilustrações pode ser uma estratégia de ensino eficiente, não só para esses alunos, mas para todos.

Vários autores observaram tal tema, como Dondis (1997) que fundamenta a importância do caráter visual dos elementos gráficos como multilateral, desde a identificação de objetos ao uso simbólico. Paivio (apud Sadoski, 1999) em sua Teoria do Código Duplo (Dual Coding Theory) quando propôs que a informação é processada 
através de dois canais distintos e independentes: um processa a informação verbal (texto e fala) enquanto o outro processa a informação não-verbal (imagens e sons do ambiente). Os canais estão conectados entre si: uma palavra pode nos remeter a uma imagem e vice-versa. Paivio defendia que informações transmitidas através dos dois canais, em redundância, são mais bem assimiladas e lembradas, pois a pessoa tem mais possibilidades (verbal e não-verbal) para buscar a informação que foi armazenada. Por fim, ele afirma que substantivos são mais facilmente relembrados do que adjetivos e que substantivos concretos mais facilmente que substantivos abstratos (ex. cadeira e aborrecido; panela e amizade), isso ocorre, pois há uma representação visual deles.

\section{PSICOLOGIA DA PERCEPÇÃO EM TEXTOS NA TERCEIRA IDADE}

Virando a página, Herbert Bayer (2010) levanta algumas questões além dessa miopia tipográfica moderna. Bayer afirma que mesmo um oculista não poderia apresentar uma prova definitiva a respeito da legibilidade porquê suas experiências são influenciadas por hábitos aos quais os pacientes estão acostumados. Mesmo uma pessoa idosa com problemas de visão, segundo ele, poderia ler facilmente um texto em estilo gótico. A questão levantada por Bayer é que não podemos considerar as letras individualmente, há outros aspectos a serem considerados além da legibilidade e a psicologia da percepção apresentaria outras questões.

O conjunto das letras, e não elas isoladas, são capturadas pelo olhar, concluiu Herbert Bayer (2010). Essa dedução nos leva a considerar as "imagens óticas de palavras" e, assim, quanto mais simples fosse sua estrutura formal mais fácil seria percebê-la e fixá-la na memória. Gombrich (2012), ao comentar sobre a leitura, defendeu que o ato de ler se pareceria mais como jogo de adivinhação. Segundo o autor, nós recorreríamos ao nosso conhecimento armazenado não apenas sobre as letras individuais, mas também sobre a linguagem e a sequência esperada de palavras. Assim, com regras finitas, a linguagem se tornaria previsível e as sequências das letras, em um contexto conhecido, nos permitiria adivinhar com facilidade, mesmo que um determinado tipo jogue contra. Araújo (2008) defende essa abordagem ao afirmar que os vocábulos mais populares são prontamente reconhecidos.

Os psicólogos da forma (gestalt) tiveram como pressupostos o princípio de que a recepção de uma imagem pelo observador significa o reconhecimento mais ou menos intuitivo da forma. Assim, a forma seria superior às partes que a compõe, a palavra superior às letras. Conclui-se que ler nesse contexto seria apreender intuitivamente as formas gerais das palavras ou grupos de palavras para formar um significado.

Todas essas questões são puras, apenas no campo das ideias, na prática precisamos de uma lupa para analisar cada situação. Os idosos, público da UNITI, estão submetidos às regras do envelhecimento e a principal questão é a perda progressiva da visão. Diante disso, torna-se ainda mais significativo considerar tais questões ao planejar artefatos didáticos. Segundo Meürer et al (2014, p.35), há quatro tipos diferentes que provocam baixa acuidade visual:

- Degeneração muscular - afeta a região central da visão provocando textos quebrados;

- Glaucoma - devido ao aumento de pressão há danos no nervo óptico, assim a visão periférica fica comprometida e a área central borrada;

- Retinopatia diabética - provoca manchas escuras no campo de visão e com isso o texto pode ficar borrado ou distorcido e 
- Catarata - ocasiona áreas de opacidade e o texto fica desbotado, nesse sentido o contraste é fundamental.

Meürer et al (2014) menciona que, na maioria das vezes, pode-se resolver o problema da legibilidade com a ampliação dos elementos visuais; daí a recorrência de várias pessoas com baixa acuidade visual utilizarem lupas; o que resolve esse problema mas reduz o campo visual e a velocidade de leitura. O Instituto Benjamim Constant, o primeiro instituto brasileiro a estudar problemas relacionados à visão, fundado em 1854, apresenta algumas recomendações entre as quais está o uso de fontes corpo 24. Independentemente do uso de tecnologias, vários dos problemas podem ser resolvidos com planejamento do material didático e usos tipográficos corretos.

\section{MÉTODO DA PESQUISA}

Para o desenvolvimento deste artigo foi realizada uma revisão bibliográfica sobre Tipografia com ênfase na legibilidade e no processo de envelhecimento. Com base na revisão bibliográfica, foi realizada uma pesquisa de campo com abordagem qualitativa. Nessa primeira fase da pesquisa não analisamos questões fisiológicas dos alunos da UNITI tampouco o desempenho dos discentes com a leitura, mas sim, realizamos uma pesquisa etnográfica com observações em sala de aula e entrevistas com os professores.

As observações ocorreram durante três semanas de aula do mês de novembro, final do ano letivo, quando a relação professor-aluno, rotinas de ensino, assimilação do vocabulário da disciplina e familiaridade com as atividades desenvolvidas já estavam consolidadas. Depois, foram realizadas entrevistas semiestruturadas com professores selecionados tendo como critério a disponibilidade. Buscou-se compreender as estratégias adotadas pelos docentes e os respectivos desempenhos dos discentes, confrontando-os com os aspectos teóricos que norteiam a investigação. Como resultado dos registros da observação e da transcrição das entrevistas foi possível elaborar uma "nuvem de palavras" com os termos mais recorrentes presentes nos dados coletados. (figura 1).

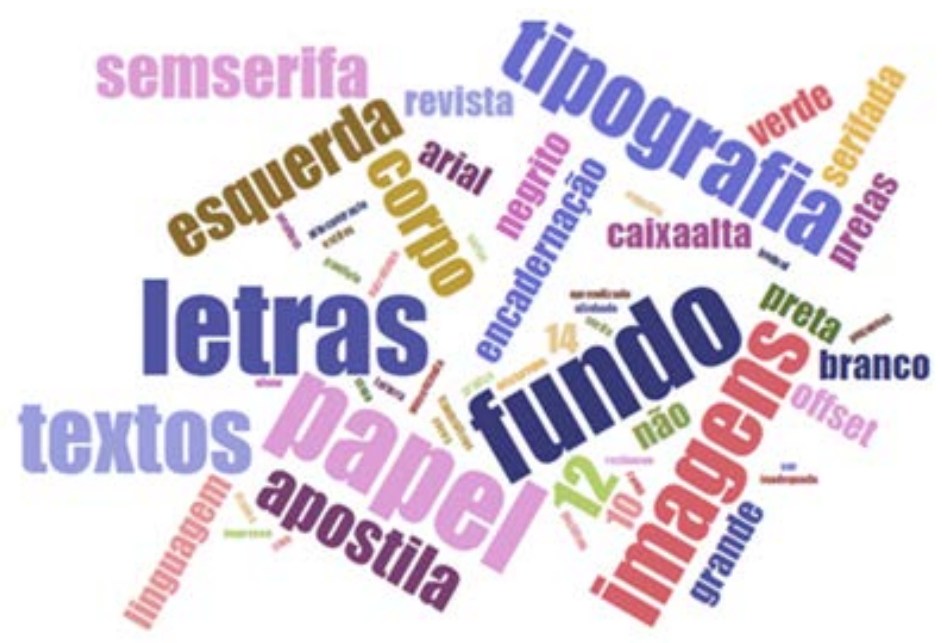

Figura 1 - Nuvem de Palavras da Pesquisa

Fonte: resultado da pesquisa etnográfica, São Luís, 2016

Mediada por essa nuvem de palavras percebe-se que algumas questões se sobressaem mais do que outras como questões relacionadas à mancha gráfica; "textos", "letras", "tipografia", "sem serifa", "serifada", "caixa alta", "negrito"e 
"corpo" são as que têm maior destaque nessa etapa da pesquisa. Questões relacionadas à percepção visual também foram notadas, tais como: relação figura e fundo, preto e branco e uso de imagens. Outros elementos valem ser citados como o material didático utilizado como "apostila", "papel offset" e tipos de encadernação. Baseado nessas relações elaborou-se uma análise a seguir.

\section{DISCUSSÃO DOS RESULTADOS}

Os professores de algumas disciplinas adotam materiais didáticos próprios, desenvolvidos para as aulas. A principal questão é entender o que significa utilizar os materiais didáticos para os alunos e professores. Podemos admitir que tal artefato é investido de significado e que investigar os sentidos nele seria um empreendimento técnico e sociológico.

A análise técnica permite perceber as características gráficas do material, como o uso de estilos tipográficos e linguagem pictórica. Quatro dos sete materiais utilizados em sala de aula foram desenvolvidos para o projeto de ensino na terceira idade e dois apresentam algumas falhas de impressão, o que compromete a leitura. Cinco de sete utilizam linguagens técnicas da própria disciplina.

A relevância em produzir o próprio material está em controlar o conteúdo didático e fornecer um instrumento de ensino completo, tanto como ferramenta para a sala de aula quanto como guia de estudo extra sala de aula. No entanto, é comum utilizar recursos caseiros para produzir imagens devido à limitação imposta pela situação de produzir o próprio material. Nesse sentido, adotar outra publicação, mesmo para um assunto pontual, pode ser uma estratégia interessante para complementar a disciplina. Porém, tais materiais não permitem o controle do conteúdo e assim pode gerar outros problemas como letras pequenas, falta e contraste etc.

Seis dos materiais analisados utilizam apenas tipografia humanista e quatro estilos industriais, sem serifa. A escolha de tais estilos talvez se dê por ser um estilo mais clássico e comum. Três utilizam mais de um estilo tipográfico. Dois materiais utilizavam uma fonte igual ou menor que 10 pts. Os demais empregaram textos com tamanhos acima de 10 pts. Sobre essa questão, algumas alunas foram indagadas e relataram que os materiais que utilizavam corpos maiores, possivelmente corpo entre 12 e 14 pts permitiriam uma melhor percepção, podiam ser lidos até mesmo sem óculos. No entanto, notaram-se, em vários momentos, usos de maiúsculas em textos longos bem como o uso de tipos leves, principalmente nas apresentações digitais dos docentes, o que poderia dificultar a leitura.

Muitos professores leram com os alunos em sala de aula o que poderia reduzir a dificuldade de leitura. Todavia, não houve uma reclamação aberta sobre tais questões. Vale destacar que vários professores tiveram cuidado com a leiturabilidade, como é o caso da disciplina de Fitoterapia a qual emprega uma linguagem coloquial como estratégia de ensino.

Ao se estabelecer um paralelo com questões teóricas sobre a tipografia, observa-se que não se pode ter uma leitura clara com caracteres pequenos. Willian Morris (2010) defendia uma paica como o tamanho mínimo de letra equivalente a 12 pts. Deduzimos que a condição geral da visão dos alunos da UNITI não é tão severa. Porém, duas discentes comentaram que as principais dificuldades estariam no contraste, com fundo colorido ou papel pardo com letras que não seriam pretas, e no analfabetismo de alguns alunos. 
A dificuldade em perceber elementos visuais pela falta de contraste pode ser explicada por alguns problemas de visão, como a catarata, reforçando a necessidade de avaliar o perfil dos alunos e intervir nos materiais gráficos utilizados. Interessante constatar que Willian Morris (2010), no final do século XIX, ao defender o livro ideal, mencionava o contraste como elemento visual fundamental para uma boa leitura. Segundo ele, o branco deveria ser claro e o preto escuro e que uma página cinza cansaria a vista; supõe-se assim que o contraste seja um item grave que dificultaria a leitura dos alunos da UNITI e o corpo tipográfico um item moderado.

Três dos sete materiais didáticos empregam apenas uma cor. Um dos materiais emprega a cor como estratégia de orientação, facilitando a navegação dos assuntos. A figura 2 apresenta alguns materiais didáticos adotados e seus elementos visuais, estilos tipográficos, contrastes de cores, etc.

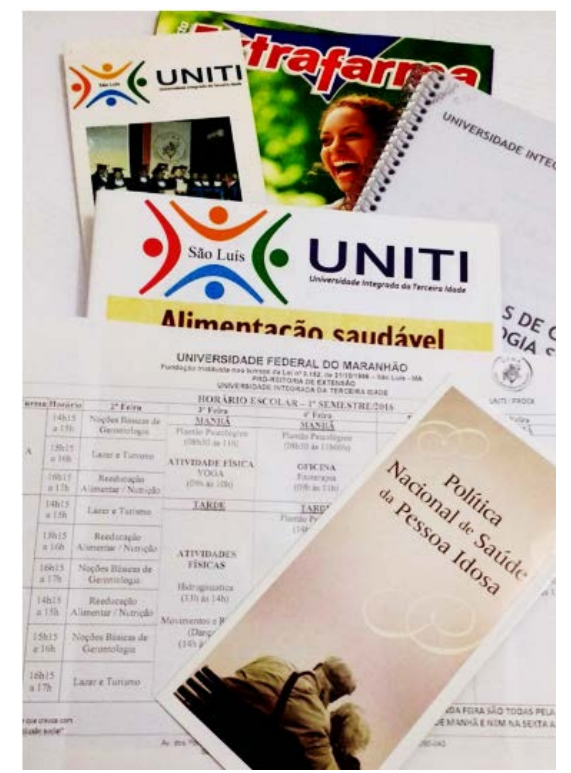

Figura 2 - Materiais didáticos adotados

Fonte: resultado da pesquisa etnográfica

A análise do perfil dos alunos e a relação com o desempenho da leitura mostrou que cerca de $25 \%$ (vinte e cinco por cento) não chegaram ao ensino médio, o que tem um peso significativo no processo de aprendizagem e nas estratégias de ensino. Por outro lado, disciplinas como Fitoterapia, Memoria e Concentração, Lazer e Turismo, pelas suas próprias características, como identificar plantas ou reconhecer lugares para que as aulas sejam desenvolvidas, requerem certo nível de conhecimento formal. Nesse sentido, não bastaria só o uso de elementos verbais, mas de elementos pictóricos.

Dondis (1997) lista uma infinidade de vantagens dos elementos pictóricos, tais: a velocidade de percepção e compreensão e proximidade com o real e interação com o meio. Empregar elementos visuais é facilitar a leitura, a compreensão e a construção de novos significados. Essas vantagens não são bem empregadas pelos materiais didáticos uma vez que apenas um material didático utiliza elementos pictóricos. No entanto, durante a observação em sala de aula, nenhum discente comentou a ausência de imagens em algumas disciplinas, tanto nas aulas expositivas quanto nos materiais gráficos, tornando o texto a principal forma de transmissão de conhecimento em vários momentos. Essa questão só veio à tona quando foram indagadas e, dessa forma, as discentes comentaram que sentem falta de tais elementos. Alguns comentaram que se os materiais didáticos empregassem imagens, 
poderiam compreender melhor, aprender mais rápido e relembrar com maior agilidade e, como diria Gombrich (2012), teria facilidade em perceber e construir o significado.

Cinco dos sete materiais didáticos têm o formato A4, que pode ser considerado inadequado para os alunos que precisam se deslocar com eles até a Universidade. Nesse sentido, Morris (2010, p.5) faz algumas ressalvas sobre os tamanhos de livros. Livros pequenos são razoavelmente confortáveis e podem ser facilmente transportados considerando o perfil dos alunos, suas idades e perfil socioeconômico, a facilidade de transporte é uma questão fundamental-. O livro grande permanece majestoso sobre o apoio, mas é desconfortável para ser transportado. De qualquer forma, muitos alunos não traziam os materiais didáticos para as salas de aula. Baseado nesse fato, levantamos várias hipóteses como: o peso do material, dificuldade em transportar e rotina pessoal conflitante.

Cada hipótese permitiria soluções específicas como: planejamento do material didático para facilitar o transporte, uso de materiais virtuais ou mesmo disponibilizar armários na UNITI. No entanto, antes de propor intervenções, faz-se necessário aprofundar o conhecimento sobre o ensino na terceira idade e discutir com os próprios alunos e professores suas questões sociais, fisiológicas e simbólicas.

\section{DESIGN E EDUCAÇÃO}

Quando o design se aproxima da educação projeta uma nova perspectiva social e permite desenvolver novos conhecimentos com novas estratégias e artefatos voltados ao ensino. No entanto, de acordo com Filatro (2007), a principal causa de fracasso na implementação do design na educação é o desconhecimento do espaço físico, organizacional e cultural. Por essa razão, tendo plena consciência da importância da relação professor-processo na sala de aula, uma das primeiras opções metodológicas dessa pesquisa foi realizar uma pesquisa etnográfica para observar as estratégias dos professores e os valores do ambiente de ensino.

A pesquisa etnográfica revelou a importância das questões sociais para os alunos da UNITI como a troca de informações, o contato com outras pessoas com experiências distintas, diversidades sociais e culturais. Tudo isso contribuiu para a internalização do conhecimento. Logo, a educação pode ser considera um processo que se desloca do plano social, das relações interpessoais, para o plano individual, das relações intrapessoais, superando diversas barreiras (físicas, cognitivas, fisiológicas, financeiras, etc.) compartilhando experiência e gerando um ambiente amistoso.

Os objetos de ensino, seja a explicação oral do professor, um slide de Datashow, dinâmicas de grupo ou artefatos didáticos, constroem representações do conhecimento. Nesse sentido, foi percebido que muitos professores, se não todos, tiveram cuidado com a linguagem utilizada em sala de aula com o intuito de facilitar a apropriação do conhecimento por parte do aluno. O design se apropria dessas representações e as materializa nos objetos de ensino traduzindo em representações verbais ou pictóricas. Tal visão permite conceber o design instrucional como um agente de transformação metafórico que traduz o conhecimento em modalidades cognitivas e sensoriais.

Para projetar artefatos didáticos, comenta Bandeira (2009), é necessário compreender a finalidade do curso, proposta-pedagógica, disciplinas e público, reforçando a necessidade de conhecer o ambiente de ensino e suas questões nela inerentes. A UNITI tem como objetivo primordial permitir uma nova reinserção social, perdida pela aposentadoria ou outras questões, sociais ou fisiológicas, promovidas pela velhice. Uma vez que conhecimento é identificado como objeto de ensino, uma série de adaptações se faz 
necessária para transformar valores e estratégias em representações e ações pedagógicas, como: desenvolver apresentações, materiais didáticos ou mesmo dinâmicas de grupo, não com a pretensão de substituir a pedagogia ou a psicologia, mas trabalhar com elas.

Nesse sentido, como citam Portugal, Couto e Gisbert (2014), o ensino pode ser um processo de autoconstrução, endógeno, cuja a origem é a percepção e cada pessoa poderá organizar seu próprio conhecimento, deslocando sua experiência social para um plano individual. Por esse motivo, devem-se priorizar as necessidades dos usuários, pensando nos materiais instrucionais ou estratégias de ensino adequados. No caso estudado, há uma grande variedade de níveis de interpretação promovidas por diversas razões, nível de escolaridade, problemas ocasionados pela velhice entre outras.

O design instrucional deve ser inclusivo e permitir que todos participem do processo de aprendizado, planejando artefatos gráficos para facilitar a legibilidade e a leiturabilidade dos textos, contemplando alunos com problemas de visão provenientes da idade avançada e amparar alunos com baixo nível de escolaridade, utilizando elementos pictóricos para facilitar o aprendizado. Desse modo, através da relação entre material didático e didática do ensino se pode compreender como certos problemas podem ser estruturados e representados, a partir da mediação do design nas relações pedagógicas.

\section{CONCLUSÃO}

Considerando o presente estudo uma etapa de um projeto maior, pode-se compreender diversas questões que estão envolvidas com os materiais didáticos na terceira idade - seja questões gráficas relacionadas ao design, seja questões relacionadas ao processo de envelhecimento e ensino na UNITI/UFMA.

Para se obter tal compreensão foi necessário um longo levantamento bibliográfico dos elementos visuais, com estudos dos elementos verbais (tipografia) e pictóricos (imagens), bem como a forma de percepção desses elementos, a influência do processo de envelhecimento e as estratégias de ensino.

Na pesquisa etnográfica foram observadas as aulas e a relação entre professor e aluno, bem como os materiais adotados e entrevista dos professores. Como resultado foi elaborado uma nuvem de palavras com a qual se pôde agrupar os temas relacionados.

O primeiro tema refere-se à análise gráfica dos materiais didáticos. Pode-se verificar que não há um cuidado com o tamanho dos tipos, tampouco com o contraste entre texto e fundo, embora alguns alunos comentarem que conseguiram ler textos em corpos menores. O contraste, devido a questões relacionadas ao processo de envelhecimento, talvez seja a questão mais delicada para esse público. Vários materiais didáticos apresentaram o uso indevido de princípios tipográficos como uso de maiúsculas em textos longos e tipografias com alto contraste na espessura, bem como não utilizaram elementos pictóricos para facilitar a compreensão de certos conceitos.

O perfil dos alunos se mostrou relevante para projetos gráficos, seja considerando o processo de envelhecimento e a necessidade de se ter uma ferramenta de auxílio à memória seja pelo nível de escolaridade que reforça ainda mais o uso de elementos pictóricos no processo de aprendizagem, seja, também, pelo critério do peso que poderia gerar um empecilho à mobilidade do aluno da terceira idade. Tais questões revelam a urgência em produzir um material próprio e adequado à realidade dos alunos e da instituição, considerando todas essas questões já citadas. 
Nesse sentido, esse estudo se tornou relevante por levantar os pontos supramencionados, considerando, entretanto, que muitos não podem ser afirmados de forma contundente, ainda que esse não tenha sido o objetivo. Demais disso pode significar inclusive ou por outro lado, há várias questões que se pretende aprofundar, como há várias possibilidades em que o design pode intervir e contribuir para construir um material didático adequado que tenha um significativo impacto no ensino na terceira idade. Pretende-se, assim, realizar estudos sobre a tipografia para uso em texto na terceira idade, avaliando estilos, tamanhos, contrastes. Almeja-se, igualmente, avaliar a importâncias dos elementos pictóricos nos artefatos didáticos para a aprendizagem dos idosos, bem como outros desdobramentos.

\section{REFERÊNCIAS}

ARAÚJO, Emanuel. A construção do livro: princípios da técnica de editoração. Rio de Janeiro: Lexikon, 2008.

BANDEIRA, Denise. Material didático. Curitiba: IESDE, 2009.

BAYER, Hebert. Rumo a uma tipologia universal. O livro ideal. In: Textos clássicos do design gráfico. São Paulo: Martins Fontes, 2010, p. 62-64.

DONDIS, Donis A. Sintaxe da linguagem visual. São Paulo: Martins Fontes, 1997.

GOLDEN, William. O tipo é para ser lido. O livro ideal. In: Textos clássicos do design gráfico. São Paulo: Martins Fontes, 2010, p. 123-128.

GOMBRICH, E.H. O sentido da ordem: um estudo sobre a psicologia da arte decorativa. Porto Alegre: Bookman, 2012.

FARIAS, Priscila Lena. Tipografia digital: o impacto das novas tecnologias. 4. ed. Teresópolis: 2AB, 2013.

FILATRO, Andréa. Design Instrucional Contextualizado: educação e tecnologia. São Paulo: SENAC, 2007.

FRUTIGER, Adrian. Sinais e símbolos. São Paulo: Martins Fontes, 2007.

HORN, Robert E. Visual Language: global communication for the 21st century. Portland: Xplane, 1998.

LUBALIN, Herb. O que há de novo na tipografia norte-americana. O livro ideal. In: Textos clássicos do design gráfico. São Paulo: Martins Fontes, 2010, p. 129-131.

LUPTON, Ellen. Novos fundamentos do design. São Paulo: Cosac Naify, 2008.

MCMURTRIE. Douglas C. A filosofia modernista na tipografia. O livro ideal. In: Textos clássicos do design gráfico. São Paulo: Martins Fontes, 2010, p. 41-45.

MEÜRER, Mary Vonni; GONÇALVES, Berenice Santos; CORREIO, Vilson João Batista. Tipografia e baixa visão: uma discussão sobre a legibilidade. In: Projética. Londrina, V.5 n.2, p. 33 - 46, dezembro. 2014.

MORRIS, Willian. O livro ideal. In: Textos clássicos do design gráfico. São Paulo: Martins Fontes, 2010, p. 1-5.

PORTUAL, Cristina; COUTO, Rita de Maria Souza; GISBERT, Juan Carlos Araño. A linha de pesquisa design em situações de ensino-aprendizagem. In: Design em situação de 
ensino-aprendizagem: 20 anos de pesquisa no laboratório interdisciplinar de design/educação. Rio de Janeiro: Rio Book's, 2014.

SHIRAIWA, Juliana Couto Silva. $O$ reconhecimento de pictogramas em interface gráfica digital pelo usuário idoso: o caso do Portal Pró-cidadão da PMF. (Dissertação) Mestrado. Universidade Federal de Santa Catarina, 2008, Florianópolis.

SKINNER, Burrhus Frederic; Vaughan, M. E. Viva bem a velhice: aprendendo a programar a sua vida. São Paulo: Summus, 1985.

SADOSKI, Mark. Theoretical, empirical and practical considerations in designing informational text. Texas, 1999.

TSCHILCHOLD, Jan. Vida nova na tipologia. O livro ideal. In: Textos clássicos do design gráfico. São Paulo: Martins Fontes, 2010, p. 46-50. 